\title{
4
}

\section{Fas Pathway of Cell Death and B Cell Dysregulation in SLE}

\author{
Roberto Paganelli, Alessia Paganelli and Maria C. Turi \\ Department of Medicine and Sciences of Aging \\ University "G. d'Annunzio" of Chieti-Pescara \\ and Ce.S.I.- U.d'A. Foundation, Chieti scalo (CH) \\ Italy
}

\section{Introduction}

Systemic lupus erythematosus (SLE) is a generalized autoimmune disease affecting several organ systems, characterized by the presence of a vast array of autoantibodies, characteristically directed to nuclear antigens (ANA) (Arbuckle et al, 2003, Hahn, 1998, Rothman and Isenberg, 2008). Systemic lupus erythematosus (SLE) is the second most common human autoimmune disease affecting between 400 and 1000 per million people worldwide (Craft, 2011).

SLE is caused by the breakdown of tolerance to nuclear self-antigens, which leads to activation of autoreactive B cells that produce autoantibodies against self-nucleic acids and associated proteins (Lande et al, 2011). These autoantibodies bind self-nucleic acids released by dying cells, and form immune complexes that are deposited in different parts of the body, leading to detrimental inflammation and tissue damage. A key early event that triggers autoimmunity in SLE is the chronic innate activation of plasmacytoid dendritic cells (pDCs) to secrete type I interferons (IFNs) (Theofilopoulos et al, 2005; Ronnblom et al, 2006; Banchereau and Pascual, 2006). The high levels of type I IFNs induce an unabated differentiation of monocytes into dendritic cells that stimulate autoreactive $\mathrm{B}$ and $\mathrm{T}$ cells (Blanco et al, 2001), licensing $\mathrm{T}$ cells recognize autoantigens and lower the activation threshold of autoreactive B cells (LeBon et al, 2006), thereby promoting autoimmunity in SLE.

Analysis of genes encoding components of the interferon pathway has led to extensive support for an association of polymorphic variants of interferon regulatory factor 5 (IRF5) with SLE (Bennett et al, 2003; Crow, 2008; Niewold et al,2007;). Recent genomewide association studies confirm associations of HLA and STAT4 variants with SLE and also the role of PTPN22 (International Consortium, 2008; Rieck et al, 2007; Remmers et al, 2007). New reports of genetic SNPs associations include the B-cell-receptor-signaling pathway and the mechanisms of adhesion of inflammatory cells to the vasculature (Hom et al, 2008; Kozyrev et al, 2008).

The heterogeneity of clinical manifestations and the disease's unpredictable course (Tan et al, 1982) characterized by flares and remissions are very likely a reflection of heterogeneity at the origin of disease, with a final common pathway leading to loss of tolerance to nuclear antigens. Impaired clearance of immune complexes and apoptotic material and production 
of autoantibodies have long been recognized as major pathogenic events (Arbuckle et al, 2003; Rothman and Isenberg, 2008). Apoptotic defects underlie some models of autoimmune diseases, and they have been proposed in the pathogenesis of SLE, a prototypic autoimmune disorder.

SLE disease activity can be difficult to monitor, and flares are unpredictable in both frequency and severity. Certain clinical laboratory tests, including anti-double-stranded DNA antibodies (anti-dsDNA), complement factor levels, and the erythrocyte sedimentation rate (ESR) are often measured as potential indicators of disease activity (Ippolito et al, 2011). Neutrophils are part of the innate immune response and they have long been suspected to play a role in SLE pathogenesis. Nevertheless, their role has not been elucidated until very recently.

In 1948, Hargraves et al. described mature bone marrow neutrophils containing intracytoplasmic nuclear material in 25 SLE patients at the Mayo Clinic (Hargraves, 1948). This phenomenon, which they called the "LE cell," helped develop the first diagnostic test for this disease (Haserick and Bortz, 1949a). In 1949, Haserick and Bortz found that plasma from 50 to $75 \%$ of patients with SLE reproduced the LE cell phenomenon in vitro, with the formation of clumps of neutrophils around amorphous masses of nuclear material (Haserick and Borts, 1949b). Subsequent reports described the LE factor binding to nuclear components, including RNPs and histones. The identification of anti-nuclear antibodies (Baugh et al, 1960; Hahn, 1998) later replaced the LE cell as a diagnostic test, and switched the focus of lupus research from neutrophils to B cells, which now seems to switch back again (see below, NETosis).

\section{Types of cell death}

In human adults, billions of cells die every day as part of the body's natural processes. Cells that become damaged by microbial infection or mechanical stress also die. The cell death that occurs in the physiological setting is programmed (Nagata et al, 2010).

Four different cell-death processes (apoptosis, cornification, necrosis, and autophagy) have been officially proposed (Kroemer et al., 2009). In apoptosis, the cell and nuclei condense and become fragmented and are engulfed by phagocytes (Kerr et al., 1972). Apoptosis is the major death process, but necrosis and autophagic cell death have also been proposed to play roles in programmed cell death (Kroemer et al., 2009). Dying cells secrete a "find me" signal, and they expose an "eat me" signal on their surface. In response to the "find me" signal, macrophages approach the dead cells; they then recognize the "eat me" signal (Ravichandran and Lorenz, 2007).

The machinery used for the engulfment and degradation of the extruded nuclei appears similar to that used for the removal of apoptotic cells. Mice deficient in the engulfment of apoptotic cells develop SLE-type autoimmune diseases (Hanayama et al., 2004). A defect in the degradation of the chromosomal DNA from engulfed cells in mice activates macrophages, leading to lethal anemia in embryos and chronic arthritis in adults (Kawane et al., 2001; Kawane et al., 2006). These observations indicate that dead cells and the nuclei expelled from erythroid precursor cells need to be swiftly cleared for animals to maintain homeostasis.

\subsection{High mobility group box 1 (HMGB1)}

In 1999, K.J. Tracey and colleagues discovered that the abundant chromatin-associated protein HMGB1 is secreted by activated macrophages during inflammation, and plays a 
critical role as a late mediator of lethal endotoxemia and sepsis (Wang et al, 1999). Since this initial report, the cytokine activity of HMGB1 has been confirmed by many groups and HMGB1 has now been proposed to be a crucial mediator in the pathogenesis of many diseases including sepsis, arthritis, and cancer (Erlandsson Harris and Andersson, 2004; Dumitriu et al, 2005; Ulloa and Messmer, 2006).

HMGB1 is an intracellular protein that when present in the extracellular milieu acts as a "necrotic marker" for the immune system. Recent studies indicate that damaged or necrotic cells can release HMGB1 into the extracellular milieu, where it triggers inflammatory responses. In contrast to necrosis, cells undergoing programmed cell death or apoptosis induce negligible inflammation in the surrounding tissue (Yang et al, 2004), which is attributed in part, to the retention of HMGB1 within the apoptotic cells (Kokkola, 2003). Indeed, there are two mechanisms for cells to liberate HMGB1 into the extracellular milieu . The first mechanism is a "passive release" of HMGB1 from damaged or necrotic cells: extracellular HMGB1 acts as an immune-stimulatory signal that indicates the extent of tissue injury (Wang et al, 2004; Yang, 2004), promotes the recruitment of mononuclear cells to clear cellular debris and protects against possible infection that often follows trauma (Carriere et al, 2007). The second mechanism is an "active secretion" of HMGB1 from immune cells to act as a pro-inflammatory cytokine during an immunological challenge.

IL-33, the most recent addition to the IL-1 family, is a potent proinflammatory cytokine that induces production of Th2-associated cytokines IL-4, IL-5, and IL-13, both in vitro and in vivo (Schmitz, 2005). Surprisingly, IL-33 has also been described as an abundant chromatin associated nuclear factor, which associates with mitotic chromosomes in living cells and with interphase chromatin in the nucleus of endothelial cells in vivo (Baekkevold, 2003). IL-33 therefore constitutes a second example of a chromatin associated cytokine (Yamada, 2007).

\subsection{NETosis}

Neutrophils in circulation are directed by cytokines into infected tissues, where they encounter invading microbes. This encounter leads to the activation of neutrophils and the engulfment of the pathogen into a phagosome. In the phagosome, two events are required for antimicrobial activity. First, the presynthesized subunits of the NADPH oxidase assemble at the phagosomal membrane and transfer electrons to oxygen to form superoxide anions. Second, the granules fuse with the phagosome, discharging antimicrobial peptides and enzymes. Together, they are responsible for microbial killing (Klebanoff, 1999). Patients with mutations in the NADPH oxidase suffer from chronic granulomatous disease (CGD; Heyworth et al., 2003).

Upon activation, neutrophils release extra cellular traps (neutrophil extracellular traps [NETs]; Brinkmann et al., 2004). NETs are composed of chromatin decorated with granular proteins, including LL-37, antibiotic peptides, neutrophil peptides and nuclear proteins, e.g. histones and HMGB1. These structures bind Gram-positive and -negative bacteria. Activated neutrophils initiate a process where first the classical lobulated nuclear morphology and the distinction between eu- and hetero-chromatin are lost. Later, all the internal membranes disappear, allowing NET components to mix. Finally, NETs emerge from the cell as the cytoplasmic membrane is ruptured by a process that is distinct from necrosis or apoptosis. This active process is dependent on the generation of ROS by NADPH oxidase (Fuchs et al., 2007). With the loss of nuclear and granular membranes, the decondensed chromatin comes into direct contact with cytoplasmic and granular 
components. 120 min after activation the granular marker neutrophil elastase colocalizes with chromatin. NETs were detected after PMA activation, but not after incubation with Fas antibody (inducing apoptosis) or treatment with $S$. aureus toxins (inducing necrosis).

Together, these data indicate that neither apoptosis nor necrosis lead to NET formation, and that NET-inducing cell death is different from both apoptosis and necrosis by morphological and molecular criteria. A hitherto unknown form of active cell death apparently evolved to allow neutrophils to kill microbes post mortem. In this form of cell death, the potent cationic antimicrobial peptides and proteins of neutrophils are mixed with chromatin and released to form NETs. Interestingly, the generation of ROS by NADPH oxidase is required for efficient phagocytic killing, and ROS act as a second messenger to trigger NET formation (Lande et al, 2011).

Importantly, in this form of cell death DNA fragmentation is not activated, allowing the chromatin to unfold in the extracellular space. NETs can bind and kill microbes by providing a high local concentration of antimicrobial peptides and, at the same time, minimize tissue damage by sequestering the noxious granule enzymes (Fuchs et al, 2007). Therefore, intact nucleosomes decorated with antimicrobial peptides and nuclear proteins may be released in NETosis, whose dysregulation has been postulated to represent a critical event in SLE pathogenesis (Craft, 2011).

\section{Cell death as driving force for autoantibodies production}

Phagocytes engulf dead cells, which are recognized as dead by virtue of a characteristic "eat me" signal exposed on their surface. Inefficient engulfment of dead cells activates the immune system, causing disease (such as SLE). The molecular details of these processes have been recently superbly reviewed in Cell (Nagata, 2010).

During apoptosis, the asymmetric distribution of phospholipids of the plasma membrane gets lost and phosphatidylserine (PS) is translocated to the outer leaflet of the plasma membrane. There, PS acts as one major "eat me" signal that ensures efficient recognition and uptake of apoptotic cells by phagocytes. PS recognition of activated phagocytes induces the secretion of anti-inflammatory cytokines like interleukin-10 (Fadok, 2001). Accumulation of dead cells containing nuclear autoantigens in sites of immune selection may provide survival signals for autoreactive B-cells.

The production of antibodies against nuclear structures determines the initiation of chronic autoimmunity in systemic lupus erythematosus. Various soluble molecules and biophysical properties of the surface of apoptotic cells play significant roles in the appropriate recognition and further processing of dying and dead cells. High mobility group box 1 (HMGB1), C-reactive protein (CRP), and anti-nuclear autoantibodies may contribute to the etiopathogenesis of the disease (Craft, 2011).

\subsection{Autoantibodies in SLE}

Patients with SLE have autoantibodies in their sera against nuclear components (antiribonucleoprotein and anti-DNA antibodies) and sometimes exhibit circulating DNA or nucleosomes (Rumore and Steinman, 1990). As unengulfed apoptotic cells are present in the germinal centers of the lymph nodes of some SLE patients and macrophages from these patients often show a reduced ability to engulf apoptotic cells, a deficiency in the clearance of apoptotic cells is proposed to be one of the causes of SLE (Gaipl et al., 2006). Apoptotic corps are disposed by phagocytes (Savill, 1994) and show immunosuppressive activity (Voll, 
1997) and recently are reported to be conducive to generation of B regulatory cells (see below) (Gray 2007).

There is increasing evidence that in systemic lupus erythematosus, nucleosomes, the basic chromatin component, represent both a driving immunogen and a major in vivo target for antibodies (Casciola-Rosen, 1994; Huggins et al, 1999). Either a disturbed apoptosis or a reduced clearance of apoptotic cells by phagocytes may lead to an increased exposure of apoptotic nucleosomes protected by HMGB1, to the immune system (Urbonaviciute et al., 2008). One possible new source of HMGB1-nucleosome complexes is thought to derive from NETosis (Lande, 2011; Garcia-Romo, 2011).

\subsection{The Fas/FasL pathway of apoptosis in SLE}

Apoptosis is activated by two pathways, the intrinsic and extrinsic pathways (Ow et al., 2008). Fas ligand (FasL), tumor necrosis factor (TNF), and TRAIL (TNF-related apoptosisinducing ligand) are type II membrane proteins that can activate the extrinsic death pathway (Krammer, 2000; Nagata, 1997; Strasser et al., 2009). The binding of FasL to its receptor (Fas) induces the formation of the death inducing signaling complex (DISC), consisting of Fas, an adaptor protein (FADD), and procaspase 8. Formation of the DISC leads to the processing and activation of caspase 8 . In both the intrinsic and extrinsic pathways, apoptosis is completed by the cleavage of a set of cellular proteins (more than 500 substrates) by effector caspases (caspases 3 and 7) (Lüthi and Martin, 2007; Timmer and Salvesen, 2007).

Fas is a $43 \mathrm{kDa}$ glycoprotein molecule which is involved in inducing apoptosis in both B and T lymphocytes (Singh, 1995). In the murine MRL/lpr/lpr model of systemic lupus erythematosus (SLE), the lymphoproliferation (lpr) mutation results in defective transcription of the gene that codes for the Fas protein. MRL mice which carry the homozygous recessive lpr mutation develop a severe early-onset genetically predetermined autoimmune syndrome. Susceptibility to SLE is found to be associated with many genes (see Table 1), one of which is APO-1/Fas gene, which is present on chromosome 10 in humans (Singh et al, 2009). The APO-1/Fas promoter contains consensus sequences for binding of several transcription factors that affect the intensity of Fas expression in cells. The mutations in the APO-1/Fas promoter are associated with risk and severity in various autoimmune diseases. A decreased rate of apoptosis may possibly be related also to elevated levels of soluble Fas (sFas) which can inhibit Fas mediated apoptosis of lymphocytes (Kruse et al, 2010).

\begin{tabular}{|c|c|c|c|c|}
\hline GENETIC & TYPE I IFN (Irf-5, etc) & $\begin{array}{c}\text { TLRs } \\
(7 \text { to } 9)\end{array}$ & $\begin{array}{c}\text { B cell R and } \\
\text { activation }\end{array}$ & $\begin{array}{c}\text { Apoptotic control } \\
\text { and disposal }\end{array}$ \\
\hline FACTORS & $\begin{array}{c}\text { Complement factors } \\
\text { (classical/alternate) }\end{array}$ & $\begin{array}{c}\text { NETs } \\
\text { control }\end{array}$ & CD4 activation & $\begin{array}{c}\text { ITGAM } \\
\text { FcGRII }\end{array}$ \\
\hline
\end{tabular}

Table 1. Possible genetic loci controlling SLE predisposition; they include antigen presentation, IFN type-I production by $\mathrm{pDCs}$, activation of autoreactive T and B cells and neutrophils, complement cascade and nucleic acid sensing and antibody signalling.

In overwhelming majority of situations alterations in Fas and FasL expression are viewed in frames of Fas-mediated apoptosis (Tinazzi et al, 2009; Nozawa, 1997). Telegina et al. (2008) tested a possible involvement of Fas-ligand-mediated "reverse signaling" in the pathogenesis of autoimmune diseases such as rheumatoid arthritis (RA) and SLE. The 
results indicated that high level of sFas in RA patient blood correlates with a high activity of disease; in SLE patients with elevated sFas level there was a correlation between sFas concentration and tissue and organ damage. In serum sFas is present in oligomeric form (Tokano, 1996). Oligomeric sFas demonstrated cytotoxicity in lymphocyte primary culture and in transformed cells, while non-toxic recombinant Fas-ligand partially blocked this effect (Telegina, 2008). Levels of sFas correlated with the percentages of activated B cells defined as CD20(+)CD38(+) cells. Serum levels of sFas correlate with percentages of activated B cells but not with that of activated T cells (Bijl, 1998). There is a significant correlation between serum concentrations of sFas and serum IL-18 in SLE patients (Sahebari, 2010). sFas and TNF $\alpha$ serum levels are increased in SLE patients (Miret et al, 2001). sFas levels seems to be secondary to TNF $\alpha$ action, which is enhanced in inflammatory conditions such as SLE. Bcl-2 antigen expression and IL-10 serum levels are related to the maintenance of SLE activity. These alterations may interfere with the apoptotic process.

\subsubsection{Role of Fas/FasL in SLE}

Fas ligand (FasL), an apoptosis-inducing member of the TNF cytokine family, and its receptor Fas are critical for the shutdown of chronic immune responses and prevention of autoimmunity. Accordingly, mutations in their genes cause severe lymphadenopathy and autoimmune disease in mice and humans. FasL function is regulated by deposition in the plasma membrane and metalloprotease-mediated shedding. $\mathrm{mFasL}$ is essential for cytotoxic activity and constitutes the guardian against lymphadenopathy, autoimmunity and cancer, whereas excess sFasL appears to promote autoimmunity (O'Reilly et al., 2009). Lymphocytes from aged autoimmune MRL/lpr mice overexpress Fas ligand (FasL), and are cytotoxic against Fas + target cells. This cytotoxic potential is only partly due to FasL, as wild-type MRL+/+ lymphocytes are not able to kill Fas+ targets after induction of FasL (Hadj-Slimane et al, 2004). IFN alpha, which is increased in SLE, induces overexpression of Fas on lymphocyte surface of lpr mice.

In healthy subjects, more memory than naive T lymphocytes undergo TNF alpha-induced apoptosis. By contrast, in patients with SLE, more naive $\mathrm{T}$ cells undergo apoptosis with TNFalpha (Habib et al, 2009). Enhanced apoptosis of T cells in SLE seems to be independent of disease activity or medication. Finally, inhibition experiments showed that apoptosis in the presence of TNFalpha was only partly blocked by anti-FasL antibody (Habib, 2009). Another study showed that $\mathrm{mFas}$ expression levels were significantly higher among SLE patients than in healthy controls, and the expression levels had a positive correlation with the early apoptosis rate of mononuclear cells in SLE patients (Li et al, 2009).

Data from several studies demonstrate increasing serum concentrations of the soluble molecules sFas and sFasL starting the first days after birth, indicating possibly a gradual decrease of apoptosis in early neonatal life (Telegina, 2009). In our study (Turi et al., 2009) SLE patients with lower ratios of sFas/sFasL in their sera were of younger age, and had a shorter disease duration (as calculated by the time from diagnosis) and also shorter duration of therapy and/or less organ damage. This pointed to the association of the index with age, which resulted to be strongly correlated with this parameter. Therefore the main variable associated with changes of the sFas/sFasL ratio is the age of the subjects.

Neutrophil apoptosis was significantly increased in patients with juvenile-onset SLE as compared with the noninflamed controls (Midgley et al, 2009). Concentrations of TRAIL and FasL were significantly increased in sera from patients with juvenile-onset SLE, but formation of NETs was not assessed in this study. Finally, it has been reported 
that SLE serum is capable of inducing apoptosis independent of Fas or TNF-R (Bengtsson et al, 2008).

\subsection{Type I Interferons and apoptosis}

Type I IFN (IFN-I) was firstly described in 1957 as a soluble factor responsible for viral resistance in vitro. IFN-I can be considered a "director" of protective immune responses (Sozzani et al, 2010). The recent finding of the so-called interferon signature in patients suffering from different autoimmune diseases has underlined its possible role in the pathogenesis of these diseases (Obermoser and Pascual, 2010). Type I IFN has immunoregulatory functions by affecting cell proliferation and by inducing antiinflammatory responses (Cantaert et al, 2010).

pDCs, specialized type I IFN producers, significantly enhance autoreactive B cell proliferation, autoantibody production, and survival in response to TLR and BCR stimulation (Thibault, 2009). IFNAR2-/- B cells fail to upregulate nucleic acid-sensing Toll-like receptors TLR7 as well as TLR9 expression in response to IFN-I (Ding et al, 2009). In addition, serum levels of IFN-alpha increase in parallel with the Fas-dependent cytotoxic potential of lymphocytes from MRL/lpr mice as they age (Hadj-Slimane, 2004). MRL/lpr lymphocytes overexpressed mRNA for the IFN-alpha receptor (IFNAR-1 and IFNAR-2) chains of the IFN-I receptor and exhibited high endogenous levels of phosphorylated Stat1. These data suggest that IFN-alpha plays an important role in the SLE-like syndrome occurring in MRL/lpr mice, and link aberrant apoptosis caused by FasL to high levels of IFN-I.

It has been found that type 1 IFNs protect human B cells in culture from spontaneous apoptosis and from apoptosis mediated by anti-CD95 agonist, in a dose- and timedependant manner (Badr et al, 2010). Such effect on human B cells was totally abrogated by blockade of IFNR1 chain. PI3Kס, Rho-A, NFKB and Bcl-2/Bcl $\mathrm{XL}_{\mathrm{L}}$ are active downstream of IFN receptors and are the major effectors of IFN-I-rescued $B$ cells from apoptosis. Furthermore, marked reduction in numbers of CD20 positive B cell in both spleen and Peyer's patches was seen in mice treated with anti-IFNR1. Type I IFNs can stimulate B-cell proliferation and differentiation into antibody-secreting plasma cells, and differentiation of immature monocytes into antigen presenting dendritic cells. These dendritic cells can activate autoreactive lymphocytes and promote autoantibody production (Ding, 2009). These functions of type I IFN, coupled with impaired clearance of apoptotic debris in SLE patients, promote formation of immune complexes, which are potent inducers of type I IFN (Craft, 2011). Inappropriate IFN production and/or an inability to dampen IFN responses thus may initiate a positive feedback loop, resulting in perpetuation of the autoimmune response.

\section{B cell phenotypes in SLE}

\subsection{B lymphocytes development}

Cells that have recently emerged from the bone marrow and have yet to acquire follicular markers such as IgD and CD23, but that express very low levels of CD21 and invariably express high levels of CD24 and AA4.1, are called T1 or newly formed (NF) B cells (Carsetti, 2004a). These cells do not require BAFF (B cell-activating factor of the TNF family) for their survival (Schneider, 2001), but like all B cells they depend on signals from the BCR for survival (Kraus, 2004; Hardy and Hayakawa, 2001). These cells, after emerging from the marginal sinus, mature and are drawn into follicles following a CXCL13 gradient (Pillai, 
2008), initially become transitional follicular B cells, and eventually give rise to at least two lineages of B cells, mature FO B cells and MZ B cells. Transitional follicular B cells can be subdivided into two distinct categories. NF (newly formed)/T1 (transitional stage 1) B cells are believed to differentiate into T2-FP (transitional stage 2-follicular precursors), which may either differentiate into mature FO B cells or sequentially into T2-MZP (transitional stage 2-MZ B cell precursors) or MZ (marginal zone) B cells (Cariappa and Pillai, 2002).

Although MZ B cells are defined primarily on the basis of their anatomical localization (Martin and Kearney, 2002), the surface expression of a number of markers can also be used to characterize these cells. In rodents the only secondary lymphoid organ in which cells bearing surface markers characteristic of MZ B cells are normally found is the spleen. Unlike follicular B cells that express high levels of IgD and CD23, with either high or low levels of IgM, MZ B cells express high levels of IgM and very low levels of IgD and CD23 (Oliver, 1999). They also express higher levels of CD21 (complement receptor type II), CD1d (an MHC class Ib protein linked to the presentation of lipid antigens), CD38 (an ADP-ribosyl cyclase), CD9 (a scavenger receptor family protein), and CD25 (the $\alpha$ chain of the IL-2 receptor) than those on follicular B cells. MZ B cells also express higher levels of B7 proteins than do follicular B cells and overall are described as having an "activated" phenotype (Oliver, 1997).

\subsubsection{Transitional B cells}

To identify human transitional B cells, two developmentally regulated markers, CD24 and CD38, are used in combination with the B-lineage marker CD19. In the peripheral blood, all cells of the B lineage (CD19pos) coexpress CD24 and CD38, and, conversely, all non-B cells (CD19neg) lack CD24. (Carsetti, 2004b) Three populations of B cells can be discriminated based on the relative distribution of CD24 and CD38. The CD24brightCD38neg population includes $60 \%$ of all B cells and only $2 \%$ expressed high levels of both CD24 and CD38 (CD24brightCD38bright). To distinguish mature from memory B cells, the expression of CD27 (a marker of memory cells) can be studied in the three populations. Essentially all CD24brightCD38neg cells are memory B cells, and mature B cells correspond to the CD24dullCD38pos population. CD24brightCD38bright cells lack CD27 (Carsetti 2004 a, b). The analysis of $\operatorname{IgM}$ and $\operatorname{IgD}$ in the CD24brightCD38bright population shows that transitional B cells coexpress IgM and IgD. IL-10 produced by B cells can downregulate autoimmune disease in EAE (Fillatreau et al., 2002), collagen-induced arthritis (Mauri et al., 2003), and inflammatory bowel disease (Mizoguchi et al., 2002). IL-10-deficient (Il10-/-) mice also have enhanced hypersensitivity responses (Berg et al., 1995). Neutralizing IL-10 by monoclonal antibody $(\mathrm{mAb})$ treatment also enhances these responses, whereas systemic IL10 administration reduces them (Ferguson et al., 1994; Schwarz et al., 1994). IL-10 is secreted by multiple cell types, including $\mathrm{T}$ cells, monocytes, macrophages, mast cells, eosinophils, and keratinocytes, and can suppress both Th1 and Th2 polarization (Yanaba, 2008) and inhibit macrophage antigen presentation and proinflammatory cytokine production (Asadullah et al., 2003). Thus, B cells and IL-10 play important inhibitory roles during T cellmediated inflammatory responses.

\subsubsection{Negative regulation by $B$ cells}

$B$ cells have been recently shown to negatively regulate autoimmunity and inflammation in numerous mouse models (Bouaziz, 2008). Mizoguchi and Bhan (2006) were the first to use 
the term 'regulatory B cells' to designate B cells with regulatory properties. Suppressor/regulatory B-cell populations have predominantly been identified using diverse mouse models of autoimmune diseases, suggesting that autoimmunity itself promotes the expansion of these cells as a compensatory mechanism to limit self-directed inflammation.

Immunological tolerance exemplifies the capacity of the immune system to downmodulate host immune responses (Shevach, 2000). Several regulatory T-cell subsets have been identified that contribute to immunological tolerance, including naturally arising CD4+CD25+Forkhead box protein 3 (FoxP3)+ regulatory T cells (Sakaguchi, 2004) and Tregulatory type 1 cells that produce high amounts of interleukin-10 (Groux, 1997). B cells are generally considered to be positive regulators of immune responses.

Whether negative regulation is a general property of B cells induced as a consequence of normal B-cell activation or whether only a specific subset of B cells posses this property has also been unknown. However, it has been recently shown that regulatory B cells are a phenotypically unique (CD1dhi CD5+) and rare subset of B cells in the spleens of naive wildtype mice that can significantly influence T-cell activation and some inflammatory responses (Yanaba, 2008). This specific subset of regulatory B cells only produces IL-10 and is responsible for most IL-10 production by B cells. Other regulatory B-cell subsets that may also exist (Mauri and Ehrestein, 2008, Bouaziz, 2008).

Stimulation of arthritogenic B cells with an agonistic anti-CD40 and collagen generated a subset of B cells producing IL-10 (Mauri, 2007). Transfer of collagen and anti-CD40stimulated Bcells to syngeneic immunized mice prevented the induction of arthritis and ameliorated established disease. This suppressive effect was associated with a downregulation of Th1 cytokines and was dependent upon the release of IL-10 because B cells isolated from IL-10- deficient mice stimulated with collagen and anti-CD40 failed to suppress disease (Mauri et al, 2007). The engagement of CD40 on B cells is also a principal requirement for the generation of Bregs in EAE. Additional in vivo results have shown that MZ B cells participate in the suppression of systemic lupus erythematosus (Lenert et al, 2005). After anti-CD40 treatment an increase of IL-10 production and a decrease of IFNgamma release was observed (Mauri, 2000) so it was suggested that the therapeutic effect observed after administration of anti-CD40, could have been achieved by redirecting pathogenic Th1 type response toward the "protective" Th2 type (Harris et al, 2000). These data show that the dialogue between B and T cells during an (auto)-immune response is not one sided and demonstrate that $\mathrm{B}$ cells have a strong impact in conditioning $\mathrm{T}$ cell differentiation.

\subsection{Breg phenotype(s)}

Further phenotypical identification showed that the majority of CD19+CD38hiCD24hi B cells were also IgMhiIgDhiCD5+CD10+CD20+CD27-CD1dhi (Blair et al, 2010). Interestingly, the majority of the CD19+CD5+CD1dhiB cells (71\%), previously reported to be regulatory in experimental models of inflammation (Matsushita et al., 2008; Yanaba et al., 2008a), are contained within the CD24hiCD38hi B cell subset. Co-culture of CD4+ T cells with CD19+CD24hiCD38hi B cells significantly suppressed the frequencies of CD4+IFN- $\gamma+$ and CD4+TNF- $\alpha+$ T cells.

The group of Mauri evaluated whether there was a numerical deficit in CD19+CD38hiCD24hi B cells in patients with SLE (Blair et al, 2010). The absolute cell numbers were not statistically different from controls. In contrast, the numbers of both CD19+CD38intCD24int and CD19+CD24hiCD38- B cells were both significantly reduced in 
SLE patients. These results suggest that the inability of SLE CD19+CD38hiCD24hi B cells to suppress the expression of proinflammatory cytokines by CD4+ T cells is unlikely to be due to a numerical deficiency. Depleting CD19+ CD38hiCD24hi B cells from PBMCs of healthy donors and SLE patients leads to an increased production of inflammatory cytokines such as IFN gamma and TNF alpha in healthy donors, suggesting an immunoregulatory effect, but this was not observed in SLE patients.

\subsection{Other novel B cell subsets}

A novel subset of circulating memory B cells with >2-fold higher levels of CD19 [CD19(hi) B cells] correlates with long-term adverse outcomes in SLE (Nicholas et al, 2008). These B cells do not appear anergic, as they exhibit high basal levels of phosphorylated Syk and ERK1/2, signal transduce in response to BCR crosslinking, and can become plasma cells in vitro. Autoreactive anti-Smith (Sm) B cells are enriched within this subset. Quantitative genetic variation in CD19 expression correlates with autoimmunity (Sato et al, 2000). CD19(hi) B cells have elevated CXCR3 levels and chemotax in response to its ligand CXCL9. Thus, CD19(hi) B cells are precursors to anti-self PCs, and identify an SLE patient subset likely to experience poor clinical outcomes (Nicholas, 2008). CD19(hi)CD21(lo/neg) B cells of uncertain origin are expanded also in common variable immunodeficiency patients with autoimmune features (Warnatz et al, 2002).

$\mathrm{B}$ cell functions are under the regulation of B cell antigen receptor (BCR)-induced signals and by specialized cell surface coreceptors, or "response regulators", which inform B cells of their microenvironment. These response regulators include CD19 and CD22 (Fujimoto and Sato, 2007). Importantly, this "CD19/CD22 loop" is significantly related to an autoimmune phenotype in mice. Thus, the CD19/CD22 loop may be a potential therapeutic target. Regulatory B cells that produce IL-10 are now recognized as an important component of the immune system .

\subsection{Role of TLR 7 and 9}

A previously uncharacterized population of $B$ cells has been recently described in aged mice, called Age-associated B cells (ABCs), which express integrin ax chain CD11c (Rubtsov et al, 2011). This subset is present also in young lupus-prone mice. Upon stimulation, CD11 $\mathrm{c}^{+} \mathrm{B}$ cells secrete autoantibodies and depletion of these cells in vivo leads to reduction of autoreactive antibodies. Toll-like receptor 7 (TLR7) is crucial for development of this B cell population. A similar population of B cells was observed in elderly women with autoimmune disease (Rubtsov et al, 2011). Age-associated mature B cells have been described also by Hao et al (2011): they are refractory to BCR and CD40 stimulation but respond to TLR9 or TLR7 stimulation and divide maximally upon combined BCR and TLR ligation, leading to Ig production and preferential secretion of IL-10. They derive from normal mature B cells but have lost the need of BLyS for survival. Finally, they present antigen effectively and favor polarization to a TH17 profile. It has been reported four years ago (Treml, 2007) that TLR9 stimulates TACI expression in all follicular and marginal zone B cells, but only BLyS enhances survival in TLR stimulated B cells. Following the exit from the bone marrow, peripheral B cells develop through transitional type 1 (T1) and transitional type 2 (T2) B-cell stages. Emerging data suggest that the T2 subset is the immediate precursor of the mature B-cell populations. T2 cells uniquely activate a proliferative, prosurvival, and differentiation program in response to B-cell antigen receptor (BCR) 
engagement. The type of signal(s) encountered by T2 cells lead to their differential maturation toward the follicular mature versus marginal zone mature B-cell populations (Su et al, 2004).

Among the principal targets of autoantibodies produced in murine SLE are nucleic acidprotein complexes, such as chromatin and ribonucleoproteins, and the envelope glycoprotein gp70 of endogenous retroviruses. The preferential production of these autoantibodies is apparently promoted by the presence of genetic abnormalities leading to defects in the elimination of apoptotic cells and to an enhanced expression of endogenous retroviruses. Moreover, recent studies revealed that the innate receptors TLR7 and TLR9 are critically involved in the activation of dendritic cells and autoreactive B cells through the recognition of endogenous DNA- or RNA-containing antigens and subsequent development of autoimmune responses against nuclear autoantigens (Santiago-Raber et al, 2009). Furthermore, the regulation of autoimmune responses against endogenous retroviral gp70 by TLR7 suggested the implication of endogenous retroviruses in this autoimmune response. Clearly, further elucidation of the precise molecular role of TLR7 and TLR9 in the development of autoimmune responses will help to develop novel therapeutic strategies and targets for SLE (Goeken et al, 2010).

\subsection{Relationship of B1 to Breg cells}

B1 cells constitute a specialized B cell lineage with remarkable properties that include spontaneous secretion of immunoglobulin, autoreactive repertoire skewing, focused memory characteristics, abnormal receptor signaling, induction of Th17 cell differentiation, and production of immunomodulatory IL-10. A particularly exciting issue is the relationship of B1 cells to regulatory B cells and the extent to which these cell types may be one and the same (Cancro, 2009).

Colonna-Romano et al (2009) describe the IgD-CD27- double-negative B cell population which is increased in the elderly. Most of these cells are $\mathrm{IgG}^{+}$. Evaluation of the telomere length and expression of the ABCB1 transporter and anti-apoptotic molecule, Bcl2, shows that they have the markers of memory $B$ cells. These cells do not act as antigen presenting cells, as indicated by the low levels of CD80 and DR, nor do they express significant levels of the CD40 molecule necessary to interact with $\mathrm{T}$ lymphocytes through the ligand, CD154 (Duffau et al, 2010). The authors hypothesize that these expanded cells are late memory or exhausted cells that have down-modulated the expression of CD27.

It is interesting to note that platelets are the main source of circulating CD154, and they can stimulate IFN typeI production from pDCs as well as ligate CD40 on autoreactive B cells (Duffau et al, 2010; Craft, 2011).

\section{SLE as the result of defects both in apoptosis control and B cell regulation}

Recent data have emerged to support the role of IFN alpha in both control of cell death and regulation of B lymphocyte functions. Two papers (Lande, 2011; Garcia-Romo, 2011) have reported the induction of neutrophil changes due to autoantibodies to DNA or RNA in immune complexes interacting with Fc $\gamma$ RIIa as well as TLRs in the presence of inflammatory cytokines and IFN type I, resulting in the formation of NETs which represent a type of cell death with DNA extrusion and release of antimicrobial peptides and cytolytic enzymes that is very effective in defence against bacteria. 


\subsection{Neutrophils, NETosis and B cells}

SLE neutrophils undergo accelerated spontaneous apoptosis in vitro, and SLE sera induce the apoptosis of healthy neutrophils, and nuclear material such as DNA and histones, which comprises the major structural components of NETs, is released in immunogenic form. The inappropriate amplification of this phenomenon in SLE perpetuates B cell stimulation to produce anti-DNA and -RNA antibodies, as well as autoantibodies to antibiotic peptides, and also, via TLR 7 and 9 interactions, IFN alpha production by pDC (Craft, 2011). IFN $\alpha$ in turn primes neutrophils for death with NET formation, which makes more immunogenic DNA and RNA available to the immune system. Both IFN- $\alpha$ and SLE serum up-regulate neutrophil TLR7 expression. In addition, sera from $\sim 40 \%$ of SLE patients contain TLR7 ligands in the form of ICs derived from antibodies recognizing small nuclear RNA/RNA binding protein complexes. These ICs have been shown to activate pDCs and induce type I IFN secretion. Anti-RNP antibodies are not efficient activators of pDCs in vitro, however, unless combined with dying cells, which provide the substrate to form ICs that might be internalized via Fc $\gamma$ RIIa.

Anti-RNP Ig-induced SLE NETosis requires FcyRIIa and endosomal TLR7 signaling and depends on the formation of ROS. Furthermore, anti-RNP antibodies induce SLE but not healthy neutrophils to secrete high levels of LL37 and HMGB1, two endogenous proteins that contribute to increase the immunogenicity and uptake of mammalian DNA by pDCs. Therefore other sources of immunogenic nuclear material has to be present, and this is provided by increased apoptosis, mostly due to Fas/FasL dysregulation, and inefficient disposal of IC due to complement and reticulo-endothelial defects.

\subsection{Fas/FasL dysregulation in SLE}

The Fas(CD95) antigen and its ligand (FasL, CD95L) are members of the TNF/TNFR families, expressed on the surface of immune and other cell types. They regulate one important extrinsic apoptotic pathway, by higher or lower expression and by their splice or cleaved soluble variants, sFas and sFasL (Sheriff et al., 2004; Tinazzi et al., 2009). Peripheral $\mathrm{T}$ cell apoptosis is upregulated in active SLE, in parallel with high expression of both membrane-bound and soluble Fas (Silvestris et al., 2003; Hao et al., 2006). Previous studies postulated that sFas down-regulates apoptosis in vitro through its blockade of the FasL of cytotoxic cells. This paradox has been examined by Silvestris et al. (2003) and Hao et al. (2006), but it is still unresolved. The situation is even more complex since autoantibodies to FasL have been detected in sera of SLE patients which contribute to inhibit apoptotic cell death of lymphocytes (Suzuki et al., 1998). In our study (Turi et al, 2009) we confirmed that though slightly increased values of both sFas and sFasL are found in SLE patients compared to normal subjects, a very scattered distribution is observed. No definitive answer to the importance of these differences may derive from examining one factor when many contribute to the final effect, so we decided to derive and index from the ratio of the values of sFas to sFasL, which is about 50 in normal controls. This ratio has been found to be lower in younger subjects, being related to age, both in SLE patients and healthy controls. Apoptosis resistance is modulated during aging, and the changes in the sFas/sFasL ratio may be involved in this phenomenon. As clarified by the study by O'Reilly (2009), sFasL does not efficiently mediate Fas-induced apoptosis, therefore its increase in serum equals to an additive anti-apoptotic mechanism in conjunction with elevated sFas circulating levels and autoantibodies to FasL. 


\section{Conclusion}

Systemic lupus erythematosus (SLE) is a chronic autoimmune disease characterized by the production of high-titer IgG autoantibodies directed against nuclear autoantigens. Type I interferon (IFN-I) has been shown to play an important pathogenic role in this disease. Common hypotheses about SLE pathogenesis suggest that environmental triggers, such as infectious agents, operate in the context of both susceptibility genes and epigenetic modifications, resulting in alterations in antigen presentation, lymphoid signaling, apoptosis, and antigen/IC clearance. Decreased numbers of neutrophils, dendritic cells, and lymphocytes are common features of SLE. pDCs accumulate at sites of inflammation such as the skin and the kidney, where they secrete type I interferon (IFN). Upon exposure to SLE serum, healthy monocytes differentiate into mature DCs in an IFN-I-dependent fashion. SLE display a type I IFN signature as measured by peripheral blood mononuclear cell (PBMC) gene expression profiling. The second most prevalent PBMC transcriptional signature corresponds to neutrophil-specific genes, and differential expression of these genes correlates with disease activity. Indeed, polymorphisms in genes expressed by neutrophils, such as ITGAM/CD11b, rank among the highest in the scale of SLE susceptibility. Polymorphisms in genes along the IFN and TLR signaling pathways (that is, IRF5, TLR7, IRAK1, STAT4, etc.) could amplify the response of SLE neutrophils to TLR7 triggering. Polymorphisms affecting thresholds of B cell activation and/or deficient removal of ICs might contribute to prolonged neutrophil exposure to activating ICs. Polymorphisms in FcgRIIa could affect the internalization and/or endosomal trafficking of SLE-specific ICs in neutrophils and pDCs.

Our review has highlighted some recent aspects of the main points relating to these issues, both at the cellular and molecular level, with discussion of the role of NETs formation, TLR 7/9 signaling, apoptosis increased proneness, and the induction both of autoantibodies and IFN-I overproduction. The consequences of these pathogenetic changes are then defined in terms of autoantigens presentation, B lymphocyte dysregulation and IC formation with organ damage. We mainly studied the alterations occurring at quantitative and functional level in the Fas/FasL apoptotic pathway, but also touched upon several other issues such as the relationship of newly identified B cell subsets to autoimmunity, and the role of nuclear cytokines in autoantibody stimulation. We believe that the key aspects of SLE pathogenesis have now been uncovered, and await the composition of their temporal sequence in a unified view of this multifaceted systemic autoimmune disorder.

\section{Acknowledgments}

Studies reported here have been supported by grants of the Faculty of Medicine of Chieti (60\%) for 2009-11 and PRIN 2009 from the Italian Ministry of University (MIUR) to R.P. Studies on B reg have been carried out by M.C.T. as part of a PhD Fellowship at the University of Chieti.

\section{Note added in proof}

Since completion of this chapter, a review was published in the section of Clinical implications of Basic research of the N Engl J Med (Bosch X (2011). Systemic lupus erythematosus and the neutrophil. N Engl J Med 365;8 (Aug.25) 758-60) discussing the work 
of Lande and Garcia-Romo reviewed here. No mention of HMGB1 is to be found in the review, however much emphasis was put on antimicrobial peptides (LL-37, which is also implicated in psoriasis) and antagonistic molecules for TLR signalling; the main message was on the new therapeutic aspects and the generalization of these findings (of neutrophil NETosis as pathogenetic mechanism) to vasculitis with ANCA antibodies.

\section{References}

Arbuckle MR, Mc Clain MT, Rubertone MV, Scofield RH, Dennis GJ, James JA, Harley JB (2003). Development of autoantibodies before the clinical onset of systemic lupus erythematosus. N Engl J Med 349:1526-33.

Asadullah, K., Sterry, W., and Volk, H.D. (2003). Interleukin-10 therapy-review of a new approach. Pharmacol. Rev. 55, 241-269.

Badr G, Saad H, Waly H, Hassan K, Abdel-Tawab H, Alhazza IM, Ahmed EA. (2010). Type I interferon (IFN-alpha/beta) rescues B-lymphocytes from apoptosis via PI3Kdelta/Akt, Rho-A, NFkappaB and Bcl-2/Bcl(XL). Cell Immunol. 263:31-40.

Baekkevold, E.S. et al. (2003) Molecular characterization of NF-HEV, a nuclear factor preferentially expressed in human high endothelial venules. Am. J. Pathol. 163, 6979

Banchereau J., V. Pascual (2006). Type I interferon in systemic lupus erythematosus and other autoimmune diseases. Immunity 25, 383-392

Baugh C. W., P. M. Kirol, M. V. Sachs, (1960). Demonstration and titration of anti-nuclear antibodies in systemic lupus erythematosus. Can. Med. Assoc. J. 83, 571-580.

Bengtsson AA, Gullstrand B, Truedsson L, Sturfelt G. (2008). SLE serum induces classical caspase-dependent apoptosis independent of death receptors. Clin Immunol. 126:57-66.

Bennett L., A. K. Palucka, E. Arce, V. Cantrell, J. Borvak, J. Banchereau, V. Pascual, (2003). Interferon and granulopoiesis signatures in systemic lupus erythematosus blood. J. Exp. Med. 197, 711-723

Berg, D.J., Leach, M.W., Kuhn, R., Rajewsky, K., Muller, W., Davidson, N.J., and Rennick, D. (1995). Interleukin 10 but not interleukin 4 is a natural suppressant of cutaneous inflammatory responses. J. Exp. Med. 182, 99-108.

Bijl M, van Lopik T, Limburg PC, Spronk PE, Jaegers SM, Aarden LA, Smeenk RJ, Kallenberg GG. (1998). Do elevated levels of serum-soluble fas contribute to the persistence of activated lymphocytes in systemic lupus erythematosus? J Autoimmun. 11:457-63.

Blair PA, Noreña LY, Flores-Borja F, Rawlings DJ, Isenberg DA, Ehrenstein MR, Mauri C. (2010). CD19(+) CD24(hi)CD38(hi) B cells exhibit regulatory capacity in healthy individuals but are functionally impaired in systemic Lupus Erythematosus patients. Immunity. 32:129-40.

Blanco P., A. K. Palucka, M. Gill, V. Pascual, J. Banchereau, (2001). Induction of dendritic cell differentiation by IFN-a in systemic lupus erythematosus. Science 294, 1540-1543

Bouaziz JD, Yanaba K, Tedder TF. (2008) Regulatory B cells as inhibitors of immune responses and inflammation. Immunol Rev. 224:201-14.

Brinkmann, V., U. Reichard, C. Goosmann, B. Fauler, Y. Uhlemann, D.S. Weiss, Y. Weinrauch, and A. Zychlinsky. (2004). Neutrophil extracellular traps kill bacteria. Science. 303:1532-1535. 
Cancro MP, Y Hao, JL. Scholz, RL. Riley, D Frasca, DK. Dunn-Walters, BB. Blomberg (2009) B cells and aging: molecules and mechanisms. Trends Immunol. 30: 313-318.

Cantaert T, Baeten D, Tak PP and van Baarsen LGM. (2010). Type I IFN and TNFa crossregulation in immune-mediated infl ammatory disease: basic concepts and clinical relevance. Arthr Res Ther 12:219.

Cariappa A, Pillai S. (2002). Antigen dependent B-cell development. Curr Opin Immunol 14:241-9.

Carriere, V. et al. (2007) IL-33, the IL-1-like cytokine ligand for ST2 receptor, is a chromatinassociated nuclear factor in vivo. Proc. Natl. Acad. Sci. U. S. A. 104, 282-287.

Carsetti R. (2004a) Characterization of B-cell maturation in the peripheral immune system. Methods Mol Biol. 271:25-35.

Carsetti R, Rosado MM, Wardmann H. (2004b) Peripheral development of B cells in mouse and man. Immunol Rev. 197:179-91.

Casciola-Rosen, L. A., G. Anhalt, and A. Rosen. (1994). Autoantigens targeted in systemic lupus erythematosus are clustered in two populations of surface structures on apoptotic keratinocytes. J. Exp. Med. 179: 1317-1330.

Colonna-Romano G, M Bulati, A Aquino, M Pellicanò, S Vitello, D Lio, G Candore and C Caruso (2009). A double-negative (IgD-CD27-) B cell population is increased in the peripheral blood of elderly people. Mech Ageing Dev 130: 681-90.

Craft J (2011). Dissecting the immune cell mayhem that drives lupus pathogenesis. Sci Transl Med 3, 73ps9.

Crow M.K. (2008). Collaboration, Genetic Associations, and Lupus Erythematosus. N Engl J Med 358: 956-61.

Ding C, Cai Y, Marroquin J, Ildstad ST, Yan J. (2009). Plasmacytoid dendritic cells regulate autoreactive B cell activation via soluble factors and in a cell-to-cell contact manner. J Immunol. 183:7140-9.

Duffau P., J. Seneschal, C. Nicco, C. Richez, E. Lazaro, I. Douchet, C. Bordes, J.-F. Viallard, C. Goulvestre, J.-L. Pellegrin, B. Weil, J.-F. Moreau, F. Batteux, P. Blanco (2010). Platelet CD154 potentiates interferon-a secretion by plasmacytoid dendritic cells in systemic lupus erythematosus. Sci. Transl. Med. 2, 47ra63.

Dumitriu, I. E., P. Baruah, A. A. Manfredi, M. E. Bianchi, and P. Rovere-Querini. (2005). HMGB1: guiding immunity from within. Trends Immunol. 26: 381-387.

Erlandsson Harris, H., and U. Andersson. (2004). Mini-review: the nuclear protein HMGB1 as a proinflammatory mediator. Eur. J. Immunol. 34: 1503-1512.

Fadok, V.A., Bratton, D.L., Guthrie, L., and Henson, P.M. (2001). Differential effects of apoptotic versus lysed cells on macrophage production of cytokines: role of proteases. J. Immunol. 166, 6847-6854.

Ferguson, T.A., Dube, P., and Griffith, T.S. (1994). Regulation of contact hypersensitivity by interleukin 10. J. Exp. Med. 179, 1597-1604.

Fillatreau, S., Sweenie, C.H., McGeachy, M.J., Gray, D., and Anderton, S.M. (2002). B cells regulate autoimmunity by provision of IL-10. Nat. Immunol. 3, 944-950.

Fuchs TA,U Abed, C Goosmann, R Hurwitz, I Schulze, V Wahn, Y Weinrauch, V Brinkmann, A Zychlinsky (2007) Novel cell death program leads to neutrophil extracellular traps. J Cell Biol 176, 231-241. 
Fujimoto M, Sato S. (2007). B cell signaling and autoimmune diseases: CD19/CD22 loop as a B cell signalling device to regulate the balance of autoimmunity. J Dermatol Sci. 46:1-9.

Gaipl, U.S., Kuhn, A., Sheriff, A., Munoz, L.E., Franz, S., Voll, R.E., Kalden, J.R., and Herrmann, M. (2006). Clearance of apoptotic cells in human SLE. Curr. Dir. Autoimmun. 9, 173-187.

Garcia-Romo G.S., S. Caielli, B. Vega, J. Connolly, F. Allantaz, Z. Xu, M. Punaro, J. Baisch, C.Guiducci, R. L.Coffman, F. J.Barrat, J. Banchereau,V. Pascual, (2011). Netting neutrophils are major inducers of type I IFN production in pediatric systemic lupus erythematosus. Sci. Transl. Med. 3, 73ra20

Goeken JA, T Layer, S Fleenor, M Laccheo and P Lenert (2010) B-cell receptor for antigen modulates B-cell responses to complex TLR9 agonists and antagonists: implications for systemic lupus erythematosus. Lupus 19, 1290-1301.

Gray M, Miles K, Salter D, Gray D, Savill J. (2007). Apoptotic cells protect mice from autoimmune inflammation by the induction of regulatory B cells. Proc Natl Acad Sci USA 104:14080-5

Groux, H., A. O'Garra, M. Bigler, M. Rouleau, S. Antonenko, J. E. de Vries, and M. G. Roncarolo. (1997). A CD4+ T cell subset inhibits antigen-specific $\mathrm{T}$ cell responses and prevents colitis. Nature 389: 737-742.

Habib HM, Taher TE, Isenberg DA, Mageed RA. (2009). Enhanced propensity of T lymphocytes in patients with systemic lupus erythematosus to apoptosis in the presence of tumour necrosis factor alpha. Scand J Rheumatol. 38:112-20.

Hadj-Slimane R, Chelbi-Alix MK, Tovey MG, Bobé P. (2004). An essential role for IFN-alpha in the overexpression of Fas ligand on MRL/lpr lymphocytes and on their spontaneous Fas-mediated cytotoxic potential. J Interferon Cytokine Res. 24:717-28.

Hahn BH (1998). Antibodies to DNA. N Engl J Med 338:1359-68.

Hanayama, R., Tanaka, M., Miyasaka, K., Aozasa, K., Koike, M., Uchiyama, Y., and Nagata, S. (2004). Autoimmune disease and impaired uptake of apoptotic cells in MFG-E8deficient mice. Science 304, 1147-1150.

Hao, J.H., Ye, D.Q., Zhang, G.Q., Liu, H.H., Dai, H., Huang, F., Pan, F.M., Su, H., Dong, M.X., Chen, H., Wang, Q., Zhang, X.J. (2006): Elevated levels of serum soluble Fas are associated with organ and tissue damage in systemic lupus erythematosus among Chinese. Arch. Dermatol. Res. 297, 329-332.

Hao Y, O'Neill PJ, Naradikian MS, Scholz JL, Cancro MP. (2011). A B-cell subset uniquely responsive to innate stimuli accumulates in aged mice. Blood. 118:1294-304

Hardy RR, Hayakawa K. (2001). B cell development pathways. Annu. Rev. Immunol. 19:595621

Hargraves M.M., H. Richmond, R. Morton, (1948). Presentation of two bone marrow elements; the tart cell and the L.E. cell. Mayo Clin. Proc. 23, 25-28

Harris, D.P., L. Haynes, P.C. Sayles, D.K. Duso, S.M. Eaton, N.M. Lepak, L.L. Johnson, S.L. Swain, and F.E. Lund. (2000). Reciprocal regulation of polarized cytokine production by effector B and T cells. Nat. Immunol. 1:475-482.

Haserick J.R., D. W. Bortz (1949a). A new diagnostic test for acute disseminated lupus erythematosus. Cleve. Clin. Q. 16, 158-161

Haserick J.R., D. W. Bortz, (1949b). Normal bone marrow inclusion phenomena induced by lupus erythematosus plasma. J. Invest. Dermatol. 13, 47-49. 
Heyworth, P.G., A.R. Cross, and J.T. Curnutte. (2003). Chronic granulomatous disease. Curr. Opin. Immunol. 15:578-584.

Hom G, Graham RR, Modrek B, et al. (2008) Association of systemic lupus erythematosus with C8orf13-BLK and ITGAM-ITGAX. N Engl J Med 358: 900-909.

Huggins, M. L., I. Todd, M. A. Cavers, S. R. Pavuluri, P. J. Tighe, and R. J. Powell. (1999). Antibodies from systemic lupus erythematosus (SLE) sera define differential release of autoantigens from cell lines undergoing apoptosis. Clin. Exp. Immunol.118: 322-328.

International Consortium for Systemic Lupus Erythematosus Genetics, Harley JB, AlarconRiquelme ME, et al. (2008). A genomewide association scan in women with systemic lupus erythematosus identifies risk variants in ITGAM, PXK, KIAA1542 and other loci and confirms multiple loci contributing to disease susceptibility. Nat Genet 40, 204-210

Ippolito A., DJ Wallace, D Gladman, PR Fortin, M Urowitz, V Werth, M Costner, C Gordon, GS Alarcón, R et al. (2011) Autoantibodies in systemic lupus erythematosus: comparison of historical and current assessment of seropositivity. Lupus 20, 250255.

Kawane, K., Fukuyama, H., Kondoh, G., Takeda, J., Ohsawa, Y., Uchiyama, Y., and Nagata, S. (2001). Requirement of DNase II for definitive erythropoiesis in the mouse fetal liver. Science 292, 1546-1549.

Kawane, K., Ohtani, M., Miwa, K., Kizawa, T., Kanbara, Y., Yoshioka, Y., Yoshikawa, H., and Nagata, S. (2006). Chronic polyarthritis caused by mammalian DNA that escapes from degradation in macrophages. Nature 443,998-1002.

Kerr, J.F., Wyllie, A.H., and Currie, A.R. (1972). Apoptosis: a basic biological phenomenon with wide-ranging implications in tissue kinetics. Br. J. Cancer 26, 239-257.

Klebanoff, S.J. (1999). Oxygen metabolites from phagocytes. In J.I. Gallin and R. Snyderman, editors. Infl ammation: Basic Principles and Clinical Correlates. Lippincott Williams \& Wilkins, Philadelphia. 721-768

Kokkola R, Li J, Sundberg E, Aveberger AC, Palmblad K, Yang H, et al. (2003) Successful treatment of collagen-induced arthritis in mice and rats by targeting extracellular high mobility group box chromosomal protein 1 activity. Arthritis Rheum 48:20528.

Kozyrev SV, Abelson A-K, Wojcik J, et al. (2008) Functional variants in the B cell gene BANK1 are associated with systemic lupus erythematosus. Nat Genet 40: 211-216.

Krammer, P.H. (2000). CD95's deadly mission in the immune system. Nature 407, 789-795.

Kraus M, Alimzhanov MB, Rajewsky N, Rajewsky K. (2004). Survival of resting mature B lymphocytes depends on BCR signaling via the Iga/ $\beta$ heterodimer. Cell 117:787-800

Kroemer, G., Galluzzi, L., Vandenabeele, P., Abrams, J., Alnemri, E.S., Baehrecke, E.H., Blagosklonny, M.V., El-Deiry, W.S., Golstein, P., Green, D.R., et al; Nomenclature Committee on Cell Death 2009. (2009). Classification of cell death: recommendations of the Nomenclature Committee on Cell Death 2009. Cell Death Differ. 16, 3-11.

Kruse K, Janko C, Urbonaviciute V, Mierke CT, Winkler TH, Voll RE, Schett G, Muñoz LE, Herrmann M. (2010). Inefficient clearance of dying cells in patients with SLE: antidsDNA autoantibodies, MFG-E8, HMGB-1 and other players. Apoptosis. 15:1098113. 
Lande R, D. Ganguly, V. Facchinetti, L. Frasca, C. Conrad, J. Gregorio, S. Meller, G. Chamilos, R. Sebasigari, V. Riccieri, R. Bassett, H. Amuro, S. Fukuhara, T. Ito, Y.-J. Liu, M. Gilliet, (2011). Neutrophils activate plasmacytoid dendritic cells by releasing self-DNA-peptide complexes in systemic lupus erythematosus. Sci. Transl. Med. 3, 73ra19

Le Bon A., C. Thompson, E. Kamphuis, V. Durand, C. Rossmann, U. Kalinke, D. F. Tough (2006). Cutting edge: Enhancement of antibody responses through direct stimulation of B and T cells by type I IFN. J. Immunol. 176, 2074-2078.

Lenert, P., R. Brummel, E. H. Field, and R. F. Ashman. (2005). TLR-9 activation of marginal zone B cells in lupus mice regulates immunity through increased IL-10 production. J. Clin. Immunol. 25: 29-40.

Li LH, Li WX, Wu O, Zhang GQ, Pan HF, Li XP, Xu JH, Dai H, Ye DQ. (2009). Fas expression on peripheral blood lymphocytes in systemic lupus erythematosus: relation to the organ damage and lymphocytes apoptosis. Mol Biol Rep. 36:2047-52.

Loken MR, Shah VO, Hollander Z, Civin CI. (1988). Flow cytometric analysis of normal B lymphoid development. Pathol Immunopathol Res. 7:357-70.

Lüthi, A.U., and Martin, S.J. (2007). The CASBAH: a searchable database of caspase substrates. Cell Death Differ. 14, 641-650.

Martin F, Kearney JF. (2002). Marginal zone B cells. Nat. Rev. Immunol. 2:323- 35

Mauri, C., L.T. Mars, and M. Londei. (2000). Therapeutic activity of agonistic monoclonal antibodies against CD40 in a chronic autoimmune inflammatory process. Nat. Med. 6:673-679.

Mauri, C., Gray, D., Mushtaq, N., and Londei, M. (2003). Prevention of arthritis by interleukin 10-producing B cells. J. Exp. Med. 197, 489-501.

Mauri, C. and Ehrenstein, M.R. (2007) Cells of the synovium in rheumatoid arthritis. B cells. Arthritis Res. Ther. 9, 205-10.

Mauri C, Ehrenstein MR. (2008). The 'short' history of regulatory B cells. Trends Immunol 29:34-40.

Midgley A, McLaren Z, Moots RJ, Edwards SW, Beresford MW. (2009). The role of neutrophil apoptosis in juvenile-onset systemic lupus erythematosus. Arthritis Rheum. 60:2390-401.

Miret C, Font J, Molina R, Garcia-Carrasco M, Filella X, Ramos M, Cervera R, Ballesta A, Ingelmo M. (2001). Relationship of oncogenes (sFas, Bcl-2) and cytokines (IL-10, alfa-TNF) with the activity of systemic lupus erythematosus. Anticancer Res. 21(4B):3053-9.

Mizoguchi, A., Mizoguchi, E., Takedatsu, H., Blumberg, R.S., and Bhan, A.K. (2002). Chronic intestinal inflammatory condition generates IL-10-producing regulatory B cell subset characterized by CD1d upregulation. Immunity 16,219-230.

Mizoguchi A, Bhan AK. (2006). A case for regulatory B cells. J Immunol. 176:705-10.

Moschese V, Orlandi P, Di Matteo G, Chini L, Carsetti R, Di Cesare S, Rossi P. (2004). Insight into B cell development and differentiation. Acta Paediatr Suppl. 93(445):48-51.

Nagata, S. (1997). Apoptosis by death factor. Cell 88, 355-365.

Nagata S, Hanayama R, Kawane K (2010). Autoimmunity and the clearance of dead cells. Cell 140: 619-630. 
Nicholas MW, Dooley MA, Hogan SL, Anolik J, Looney J, Sanz I, Clarke SH. (2008). A novel subset of memory B cells is enriched in autoreactivity and correlates with adverse outcomes in SLE. Clin Immunol. 126:189-201.

Niewold TB, Hua J, Lehman TJ, Harley JB, Crow MK. (2007). High serum IFN-alpha activity is a heritable risk factor for systemic lupus erythematosus. Genes Immun 8:492-502.

Nozawa, K., Kayagaki, N., Tokano, Y., Yagita, H., Okumura, K., Hasimoto, H. (1997): Soluble Fas (APO-1, CD95) and soluble Fas ligand in rheumatic diseases. Arthritis Rheum. 40, 1126-1129.

Obermoser G, Pascual V. (2010). The interferon-alpha signature of systemic lupus erythematosus. Lupus. 19:1012-9.

Oliver AM, Martin F, Gartland GL, Carter RH, Kearney JF. (1997). Marginal zone B cells exhibit unique activation, proliferative and immunoglobulin secretory responses. Eur. J. Immunol. 27:2366-74

Oliver AM, Martin F, Kearney JF. (1999). IgMhighCD21high lymphocytes enriched in the splenic marginal zone generate effector cells more rapidly than the bulk of follicular B cells. J. Immunol. 162:7198-207

O' Reilly LA, Tai L, Lee L, Kruse EA, Grabow S, Fairlie WD, Haynes NM, Tarlinton DM, Zhang JG, Belz GT, Smyth MJ, Bouillet P, Robb L, Strasser A. (2009). Membranebound Fas ligand only is essential for Fas-induced apoptosis. Nature. 461(7264):659-63.

Ow, Y.P., Green, D.R., Hao, Z., and Mak, T.W. (2008). Cytochrome c: functions beyond respiration. Nat. Rev. Mol. Cell Biol. 9, 532-542.

Pillai, S., A. Cariappa, and S. T. Moran. (2005). Marginal zone B cells. Annu. Rev.Immunol. 23: 161-196.

Ravichandran, K.S., and Lorenz, U. (2007). Engulfment of apoptotic cells: signals for a good meal. Nat. Rev. Immunol. 7, 964-974.

Remmers EF, Plenge RM, Lee AT, et al. (2007). STAT4 and the risk of rheumatoid arthritis and systemic lupus erythematosus. N Engl J Med 357:977-86.

Rieck M, Arechiga A, Onengut-Gumuscu S, Greenbaum C, Concannon P, Buckner JH. (2007). Genetic variation in PTPN22 corresponds to altered function of T and B lymphocytes. J Immunol 179:4704-10.

Rönnblom L, Eloranta ML, Alm GV. (2006). The type I interferon system in systemic lupus erythematosus. Arthritis Rheum 54:408-20.

Rothman A, Isenberg DA (2008). Systemic lupus erythematosus. N Engl J Med 358:929-39.

Rubtsov A.V. , K Rubtsova, A Fischer, R T. Meehan, J Z. Gillis, JW. Kappler, and P Marrack (2011) TLR7-driven accumulation of a novel CD11 ${ }^{+}$B-cell population is important for the development of autoimmunity. Blood. 118(5):1305-15

Rumore, P.M., and Steinman, C.R. (1990). Endogenous circulating DNA in systemic lupus erythematosus. Occurrence as multimeric complexes bound to histone. J. Clin. Invest. 86, 69-74.

Sahebari M, Rezaieyazdi Z, Nakhjavani MJ, Hatef M, Mahmoudi M, Akhlaghi S. (2010). Correlation between serum concentrations of soluble Fas (CD95/Apo-1) and IL-18 in patients with systemic lupus erythematosus. Rheumatol Int. DOI: $10.1007 /$ s00296-010-1633-9 
Sakaguchi, S. (2004). Naturally arising CD4_ regulatory T cells for immunologic self tolerance and negative control of immune responses. Ann. Rev. Immunol. 22:531562.

Salmon JE, Millard S, Schacter LA, et al. (1996). Fc gamma RIIA alleles are heritable risk factors for lupus nephritis in African Americans. J Clin Invest 97:1348-54.

Santiago-Raber M-L, L Baudino and S Izui (2009). Emerging roles of TLR7 and TLR9 in murine SLE. J Autoimmunity 33:231-8.

Sato S, Hasegawa M, Fujimoto M, Tedder TF, Takehara K. (2000). Quantitative genetic variation in CD19 expression correlates with autoimmunity. J Immunol. 165:663543.

Savill, J., V. Fadok, P. Henson, and C. Haslett. (1993). Phagocyte recognition of cells undergoing apoptosis. Immunol. Today 14: 131-136.

Schmitz J, Owyang A, Oldham E, Song Y, Murphy E, McClanahan TK, Zurawski G, Moshrefi M, Qin J, Li X, Gorman DM, Bazan JF, Kastelein RA. (2005) IL-33, an interleukin-1-like cytokine that signals via the IL-1 receptor-related protein ST2 and induces $\mathrm{T}$ helper type 2-associated cytokines. Immunity 23, 479-490

Schneider P, Takatsuka H, Wilson A, Mackay F, Tardivel A, et al. (2001). Maturation of marginal zone and follicular B cells requires B cell activating factor of the tumor necrosis factor family and is independent of B cell maturation antigen. J.Exp. Med. 194:1691-97

Sheriff, A., Gaipl, U.S., Voll, R.E., Kalden, J.R., Herrmann, M. (2004): Apoptosis and systemic lupus erythematosus. Rheum. Dis. Clin. North Am. 30, 505-527.

Shevach, E. M. (2000). Regulatory T cells in autoimmunity. Ann. Rev. Immunol. 18:423-449.

Sigurdsson S, Göring HH, Kristjansdottir G, et al. (2008). Comprehensive evaluation of the genetic variants of interferon regulatory factor 5 reveals a novel $5 \mathrm{bp}$ length polymorphism as strong risk factor for systemic lupus erythematosus. Hum Mol Genet 17:872-81.

Silvestris, F., Grinello, D., Tucci, M., Cafforio, P., Dammacco, F. (2003): Enhancement of T cell apoptosis correlates with increased serum levels of soluble Fas (CD95/Apo1)in active lupus. Lupus $12,8-14$.

Singh AK. (1995). Lupus in the Fas lane? J R Coll Physicians Lond. 29:475-8.

Singh R, Pradhan V, Patwardhan M, Ghosh K. (2009). APO-1/Fas gene: Structural and functional characteristics in systemic lupus erythematosus and other autoimmune diseases. Indian J Hum Genet. 15:98-102.

Sozzani S, Bosisio D, Scarsi M, Tincani A. (2010). Type I interferons in systemic autoimmunity. Autoimmunity. 43:196-203.

Strasser, A., Jost, P.J., and Nagata, S. (2009). The many roles of FAS receptor signaling in the immune system. Immunity 30, 180-192.

Su TT, Guo B, Wei B, Braun J, Rawlings DJ. (2004). Signaling in transitional type 2 B cells is critical for peripheral B-cell development. Immunol Rev. 197:161-78.

Suzuki, N., Ichino, M., Mihara, S., Kaneko, S., Sakane, T. (1998): Inhibition of Fas/Fas ligand-mediated apoptotic cell death of lymphocytes in vitro by circulating anti-Fas ligand autoantibodies in patients with systemic lupus erythematosus. Arthritis Rheum. 41, 344-353.

Tan EM, Cohen AS, Fries JF, et al. (1982). The 1982 revised criteria for the classification of systemic lupus erythematosus. Arthritis Rheum 25:1271-7 
Telegina E, Reshetnyak T, Moshnikova A, Proussakova O, Zhukova A, Kuznetsova A, Ivanov A, Paltsev M, Beletsky I. (2009). A possible role of Fas-ligand-mediated "reverse signaling" in pathogenesis of rheumatoid arthritis and systemic lupus erythematosus. Immunol Lett. 122:12-7.

Theofilopoulos A,N., R. Baccala, B. Beutler, D. H. Kono (2005). Type I interferons (a/b) in immunity and autoimmunity. Annu. Rev. Immunol. 23, 307-336

Thibault DL, Graham KL, Lee LY, Balboni I, Hertzog PJ, Utz PJ. (2009). Type I interferon receptor controls B-cell expression of nucleic acid-sensing Toll-like receptors and autoantibody production in a murine model of lupus. Arthritis Res Ther. 11:R112.

Timmer, J.C., and Salvesen, G.S. (2007). Caspase substrates. Cell Death Differ. 14, 66-72.

Tinazzi, E., Puccetti, A., Gerli, R., Rigo, A., Migliorini, P., Simeoni, S., Beri, R., Dolcino, M., Martinelli, N., Corrocher, R., Lunardi, C. (2009): Serum DNase I, soluble Fas/FasL levels and cell surface Fas expression in patients with SLE: a possibile explanation for the lack of efficacy of hrDNase I treatment. Int. Immunol. 21, 237-243.

Tokano, Y., Miyake, S., Kayagaki, N., Nozawa, K., Morimoto, S., Azuma, M., Yagita, H., Takasaki, Y., Okumura, K., Hashimoto, H. (1996): Soluble Fas molecule in the serum of patients with systemic lupus erythematosus. J. Clin. Immunol. 16, 261-265.

Treml LS, Carlesso G, Hoek KL, Stadanlick JE, Kambayashi T, Bram RJ, Cancro MP, Khan WN. (2007). TLR stimulation modifies BLyS receptor expression in follicular and marginal zone B cells. J Immunol. 178:7531-9.

Turi MC, D’Urbano M, Celletti E, Alessandri C, Valesini G, Paganelli R. (2009). Serum Fas/FasL ratio in sistemi lupus erythematosus (SLE) is a function of age. Arch Gerontol Geriatr S1:221-6.

Ulloa L, D Messmer (2006). High-mobility group box 1 (HMGB1) protein: Friend and foe. Cytokine \& Growth Factor Reviews 17:189-201

Urbonaviciute V, et al. (2008) Induction of infl amatory and immune responses by HMGB1 nucleosome complexes: implications for the pathogenesis of SLE. J. Exp. Med. 205:3007-3018

Voll , R.E. , M. Herrmann , E.A. Roth , C. Stach , J.R. Kalden, and I. Girkontaite . (1997). Immunosuppressive eff ects of apoptotic cells. Nature . $390: 350-351$.

Wang, H., Bloom, O., Zhang, M., Vishnubhakat, J.M.,Ombrellino, M.,Che, J., Frazier, A., Yang, H., Ivanova, S., Borovikova, L., Abraham E, Andersson J, Andersson U, Molina PE, Abumrad NN, Sama A, Tracey KJ (1999). HMG-1 as a late mediator of endotoxin lethality in mice. Science 285:248 -251.

Wang H., H. Yang \& K Tracey (2004). Extracellular role of HMGB1 in inflammation and sepsis. Journal of Internal Medicine 255: 320-331

Warnatz K, Wehr C, Dräger R, Schmidt S, Eibel H, Schlesier M, Peter HH. (2002). Expansion of CD19(hi)CD21(lo/neg) B cells in common variable immunodeficiency (CVID) patients with autoimmune cytopenia. Immunobiology. 206:502-13.

Yamada S, Maruyama I (2007). HMGB1, a novel inflammatory cytokine. Clin Chim Acta 375:36-42

Yanaba K, Bouaziz JD, Haas KM, Poe JC, Fujimoto M, Tedder TF. (2008). A regulatory B cell subset with a unique CD1dhiCD5+ phenotype controls $\mathrm{T}$ cell-dependent inflammatory responses. Immunity. 28:639-50. 
Yang H, Ochani M, Li J, Qiang X, Tanovic M, Harris HE, et al. (2004). Reversing established sepsis with antagonists of endogenous high-mobility group box 1. Proc Natl Acad Sci USA 101:296-301. 


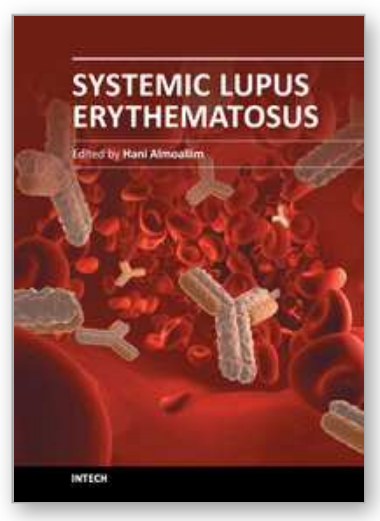

\author{
Systemic Lupus Erythematosus \\ Edited by Dr Hani Almoallim
}

ISBN 978-953-51-0266-3

Hard cover, 554 pages

Publisher InTech

Published online 21, March, 2012

Published in print edition March, 2012

This book provides a comprehensive overview of the basic and clinical sciences of Systemic Lupus Erythematosus. It is suitable for basic scientists looking for detailed coverage of their areas of interest. It describes how advances in molecular biology have increased our understanding of this disease. It is a valuable clinical resource for practicing clinicians from different disciplines including rheumatologists, rheumatology fellows and residents. This book provides convenient access to information you need about cytokines, genetics, Fas pathway, toll like receptors and atherogenesis in SLE. Animal models have been reviewed as well. How to avoid delay in SLE diagnosis and management, in addition to various clinical manifestations including pregnancy and SLE have all been explained thoroughly in this book.

\title{
How to reference
}

In order to correctly reference this scholarly work, feel free to copy and paste the following:

Roberto Paganelli, Alessia Paganelli and Maria C. Turi (2012). Fas Pathway of Cell Death and B Cell Dysregulation in SLE, Systemic Lupus Erythematosus, Dr Hani Almoallim (Ed.), ISBN: 978-953-51-0266-3, InTech, Available from: http://www.intechopen.com/books/systemic-lupus-erythematosus/fas-pathway-of-celldeath-and-b-cell-disregulation-in-sle

\section{INTECH}

open science | open minds

\section{InTech Europe}

University Campus STeP Ri

Slavka Krautzeka 83/A

51000 Rijeka, Croatia

Phone: +385 (51) 770447

Fax: +385 (51) 686166

www.intechopen.com

\section{InTech China}

Unit 405, Office Block, Hotel Equatorial Shanghai

No.65, Yan An Road (West), Shanghai, 200040, China

中国上海市延安西路65号上海国际贵都大饭店办公楼405单元

Phone: +86-21-62489820

Fax: +86-21-62489821 
(C) 2012 The Author(s). Licensee IntechOpen. This is an open access article distributed under the terms of the Creative Commons Attribution 3.0 License, which permits unrestricted use, distribution, and reproduction in any medium, provided the original work is properly cited. 